\title{
OSTEOCLASTIC DIFFERENTIATION OF MOUSE AND HUMAN MONOCYTES IN A PLASMA CLOT/BIPHASIC CALCIUM PHOSPHATE MICROPARTICLES COMPOSITE
}

\author{
Caroline C. Mouline ${ }^{1}$, Danielle Quincey ${ }^{1}$, Jean-Pierre Laugier ${ }^{2}$, Georges F. Carle ${ }^{1}$, Jean-Michel Bouler ${ }^{3}$, Nathalie \\ Rochet $^{1}$, and Jean-Claude Scimeca ${ }^{1 *}$
${ }^{1}$ GéPITOs, Université de Nice, CNRS UMR6235; UFR de Médecine, 28 Avenue de Valombrose, 06107 NICE, cedex 2, France
${ }^{2}$ Centre Commun de Microscopie Appliquée, Université de Nice-Sophia Antipolis, UFR Sciences, Parc Valrose, BP71, 06108, Nice, France
${ }^{3}$ LIOAD, Université de Nantes, INSERM UMR791, Faculté de Chirurgie Dentaire, 1 place Alexis Ricordeau, BP84215, 44042 Nantes, France

\begin{abstract}
We recently demonstrated that blood clotted around biphasic calcium phosphate (BCP) microparticles constituted a composite biomaterial that could be used for bone defect filling. In addition, we showed that mononuclear cells, i.e. monocytes and lymphocytes, play a central role in the osteogenic effect of this biomaterial. Hypothesizing that osteoclast progenitors could participate to the pro-osteogenic effect of mononuclear cells we observed previously, we focus on this population through the study of mouse monocyte/macrophage cells (RAW264.7 cell line), as well as human pre-osteoclastic cells derived from mononuclear hematopoietic progenitor cells (monocytes-enriched fraction from peripheral blood). Using monocyte-derived osteoclast progenitors cultured within plasma clot/BCP microparticles composite, we aimed in the present report at the elucidation of transcriptional profiles of genes related to osteoclastogenesis and to bone remodelling. For both human and mouse monocytes, real-time PCR experiments demonstrated that plasma clot/BCP scaffold potentiated the expression of marker genes of the osteoclast differentiation such as Nfactc1, Jdp2, Fra2, Tracp and Ctsk. By contrast, Mmp9 was induced in mouse but not in human cells, and Ctr expression was down regulated for both species. In addition, for both mouse and human precursors, osteoclastic differentiation was associated with a strong stimulation of VegfC and Sdf1 genes expression. At last, using fieldemission scanning electron microscopy analysis, we observed the interactions between human monocytes and BCP microparticles. As a whole, we demonstrated that plasma clot/BCP microparticles composite provided monocytes with a suitable microenvironment allowing their osteoclastic differentiation, together with the production of pro-angiogenic and chemoattractant factors.
\end{abstract}

Keywords: Biphasic calcium phosphate microparticles, osteoclastic differentiation, three-dimensional cell culture, VegfC, Sdf1/CXCL12, monocyte.

*Address for correspondence:

J.C. Scimeca

GéPITOs, UMR6235 UFR de Médecine,

28 Avenue de Valombrose, F-06107 NICE, cedex 2, France.

Telephone Number: +33 493-377-632

FAX Number: +3349353 3071

E-mail: scimeca@unice.fr

\section{Introduction}

Bone tissue is a highly dynamic structure that is renewed through a remodelling process involving osteoblasts and osteoclasts (Seeman and Delmas, 2006; Henriksen et al., 2009). Due to pathological conditions such as trauma or tumours, bone defects appear, and autologous bone graft is the gold standard for bridging these gaps (Sen and Miclau, 2007). However, in addition to drawbacks such as potential infection and pain at the donor site (Younger and Chapman, 1989; Arrington et al., 1996), the availability of autologous bone is limited. This prompted the development of synthetic materials as an alternative. Among these materials, ceramics based on biphasic calcium phosphate (BCP) composed of hydroxyapatite (HA) and $\beta$-tricalcium phosphate ( $\beta$-TCP) are commonly used as bone substitutes in clinical practice (Ransford et al., 1998; Cavagna et al., 1999; De Long et al., 2007; Aulakh et al., 2009).

Although ceramics based on BCP are commonly used as resorbable bone substitutes, few studies investigating the interactions between osteoclasts and particulate forms are available. In 1996, Piattelli et al. (1996) described the use for human patients of BCP granules (HA/b-TCP 50/ $50,450-600 \mathrm{~mm}$ in size) to fill bone defects resulting from the enucleation of odontogenic cysts. They reported that some degradation products of the particles were present, and they observed a gradual substitution by the bone tissue. The following year, using neonatal rabbit bone cells seeded on BCP pellets (HA/b-TCP 60/40), Yamada et al. (1997) demonstrated in vitro the existence of an osteoclastic resorption process on the BCP surface.

In the following decade, several in vivo studies reported the use of $\mathrm{BCP}$ as bone substitute to fill defects generated in rabbit (Dupraz et al., 1998; Gauthier et al., 1999b; Lu et al., 2004; Gauthier et al., 2005; Fellah et al., 2006), and these experiments highlighted the osteoconductive properties of BCP particles with a size ranging from $40 \mu \mathrm{m}$ up to $1500 \mu \mathrm{m}$. BCP was also implanted in vivo in dog (Gauthier et al., 1999a; Linton et al., 2002), rat (Malard et al., 1999; Alam et al., 2001; Lerouxel et al., 2006; Fellah et al., 2007; ) and mouse (Claase et al., 2007). Depending on the study and on the animal model, BCP microparticles $(<20 \mu \mathrm{m}, 40-500 \mu \mathrm{m})$ or larger granules $(>1000 \mu \mathrm{m})$ were used. Finally, several recent reports in the field of maxillofacial surgery for sinus augmentation document the use of BCP for human patients. With the exception of the report from Weiss et 
al. (2007) (microparticles $80-200 \mu \mathrm{m}$ in size), all these studies use a granular form of BCP (Cordaro et al., 2008; Froum et al., 2008; Sculean et al., 2008; Friedmann et al., 2009; Lindgren et al., 2009; Frenken et al., 2010; Lindgren et al., 2010).

In addition to in vivo experiments, three reports in the literature document the interactions of human cells in vitro with microparticulate forms of BCP. These studies include results published by Silva et al. (2003) about BCP microparticles ( $37 \mu \mathrm{m}$ in size) impact on human macrophages locomotion and secretion, as well as two publications that describe osteogenic differentiation of human mesenchymal stem cells associated to 1-10 $\mu \mathrm{m}$ (Saldana et al., 2009) or 140-200 $\mu \mathrm{m}$ (Cordonnier et al., 2010) microparticles.

In a recently published paper, we have demonstrated that blood or plasma clotted around BCP microparticles (40-200 $\mu \mathrm{m})$ constituted a cohesive, mouldable and adaptable biomaterial that could be used for bone defect filling (Balaguer et al., 2010). We established in that study that the osteogenic property of blood clot associated to $\mathrm{BCP}$ particles mostly resulted from the presence of mononuclear cells, which includes osteoclast progenitors present within peripheral blood monocytic cells. There is an emerging set of data supporting the notion that osteoclast-mediated resorption could benefit to bone reconstruction within a bone substitute. In synergy with the totally interconnected structure due to the microparticulate form of the BCP we use, one can hypothesize that in vivo, osteoclastic action would favour the invasion of this bone substitute by mesenchymal stem cells, vessels and osteoclastic progenitors, supporting eventually biomaterial substitution by new living bone. Using the plasma clot/BCP microparticles composite as a $3 \mathrm{D}$ cell culture system, we wanted here to identify molecules, which could account for the osteogenic property of this biomaterial. Hypothesizing that osteoclast progenitors could participate to the pro-osteogenic effect of mononuclear cells we observed previously, we focused on this population through the study of mouse monocyte/ macrophage cells (RAW264.7 cell line), as well as human pre-osteoclastic cells derived from mononuclear hematopoietic progenitor cells (monocytes-enriched fraction from peripheral blood). Using these monocytederived osteoclast progenitors, we aimed in the present report at the elucidation of transcriptional profiles of genes related to osteoclastogenesis and to bone remodelling.

\section{Materials and Methods}

\section{Cell culture}

The mouse RAW264.7 cell line was obtained from ATCC (Ref. \# TIB-71). Cells were cultured in Dulbecco's Modified Eagle's Medium (DMEM, Lonza, Basel, Switzerland) containing 5\% characterized foetal bovine serum (Hyclone serum). The RAW 264.7 cell line has been shown to readily differentiate into osteoclasts upon exposure to RANKL (Receptor Activator for Nuclear Factor $\kappa$ B Ligand). Unlike primary osteoclast precursors, there is no requirement for the addition of macrophage colony stimulating factor (M-CSF).

\section{Biphasic calcium phosphate particles}

The biphasic calcium phosphate (BCP) biomaterial was composed of $60 \%$ hydroxyapatite $\left(\mathrm{HA} ; \mathrm{Ca}_{10}\left(\mathrm{PO}_{4}\right)_{6}(\mathrm{OH})_{2}\right)$ and $40 \% \beta$-tricalcium phosphate $\left(\beta\right.$-TCP; $\left.\mathrm{Ca}_{3}\left(\mathrm{PO}_{4}\right)_{2}\right)$. The sintering conditions for BCP granules were as follows: $1050^{\circ} \mathrm{C}$ during 4 hours. Calibrated BCP particles with an equivalent diameter ranging from 80 to $200 \mu \mathrm{m}$ were provided by GRAFTYS SA (Aix en Provence, France). These particles were sterilized by heating to $180^{\circ} \mathrm{C}$ for two hours.

\section{Mouse and human cytokines}

Mouse RANKL cytokine was produced as a fusion protein with GST (GST-RANKL), as previously described (Beranger et al., 2007). For all the experiments using mouse cells, GST protein, produced and purified using the same protocol, was used in control conditions. Human recombinant cytokines hM-CSF and hRANKL were purchased from Peprotech (Rocky Hill, NJ, USA) (Recombinant Human M-CSF, \#300-25; Recombinant Human soluble RANK Ligand, \#310-01).

\section{Mouse blood withdrawal and plasma preparation}

Mouse whole blood was withdrawn on sodium citrate anticoagulant from anaesthetised ten week-old mice C57BL/6 mice (JANVIER, Le Genest St Isle, France) by intra-cardiac puncture. Plasma was obtained after blood centrifugation for $15 \mathrm{~min}$ at $2500 \mathrm{~g}$ at room temperature (RT). All the animal experiments were conducted at the central animal facility of the Faculty of Medicine according to the guidelines of the "Direction Départementale des Services Vétérinaires" and received the approval of the Local Committee for Animal Use and Care (NCA/2007/ 12-07).

\section{Plasma and human precursor cells preparation}

Human plasma and osteoclast precursors were prepared using blood samples withdrawn on sodium citrate anticoagulant from healthy donors, and obtained from EFS (Etablissement Français du Sang; www.dondusang.net). Plasma was obtained after blood centrifugation for $15 \mathrm{~min}$ at $2500 \mathrm{~g}$ at room temperature (RT). Human monocyteenriched fraction was prepared using EasySep Human Monocyte Enrichment kit from StemCell (\# 19059) according to the manufacturer's instructions. For osteoclastic differentiation, human primary osteoclast precursors required the presence of both hM-CSF and hRANKL cytokines. For each individual experiment, plasma and precursor cells were matched according to the donor.

\section{Preparation of plasma clot and plasma clot/BCP scaffolds - Precursor cells differentiation}

$3 \mathrm{D}$ cell culture scaffolds were prepared by mixing $5 \times 10^{5}$ cells and cytokines with $50 \mu \mathrm{L}$ of plasma, in the absence or in the presence of $50 \mathrm{mg}$ of BCP particles. Before 3D cell culture experiments, we performed preliminary $2 \mathrm{D}$ 
a
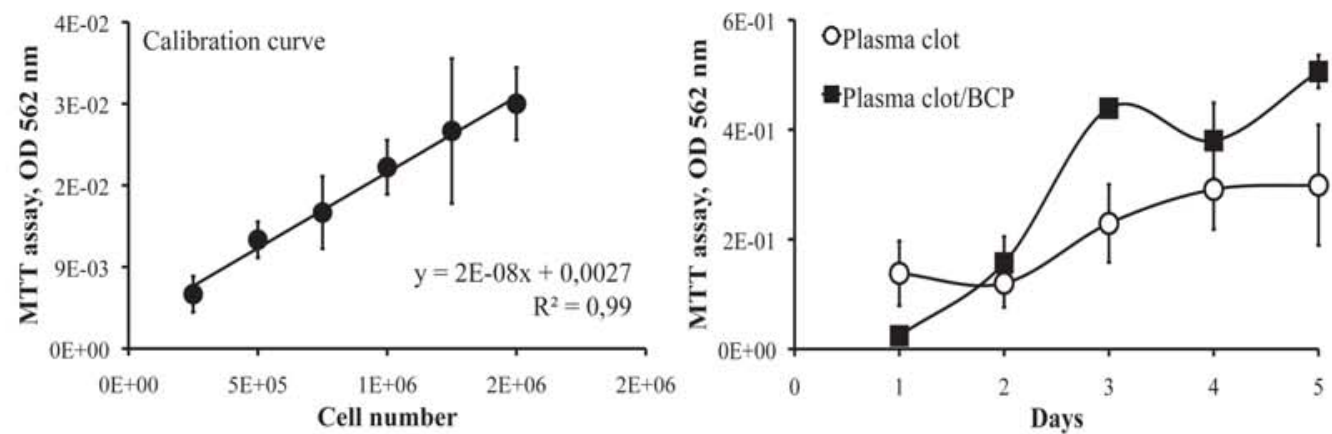

$\mathrm{b}$
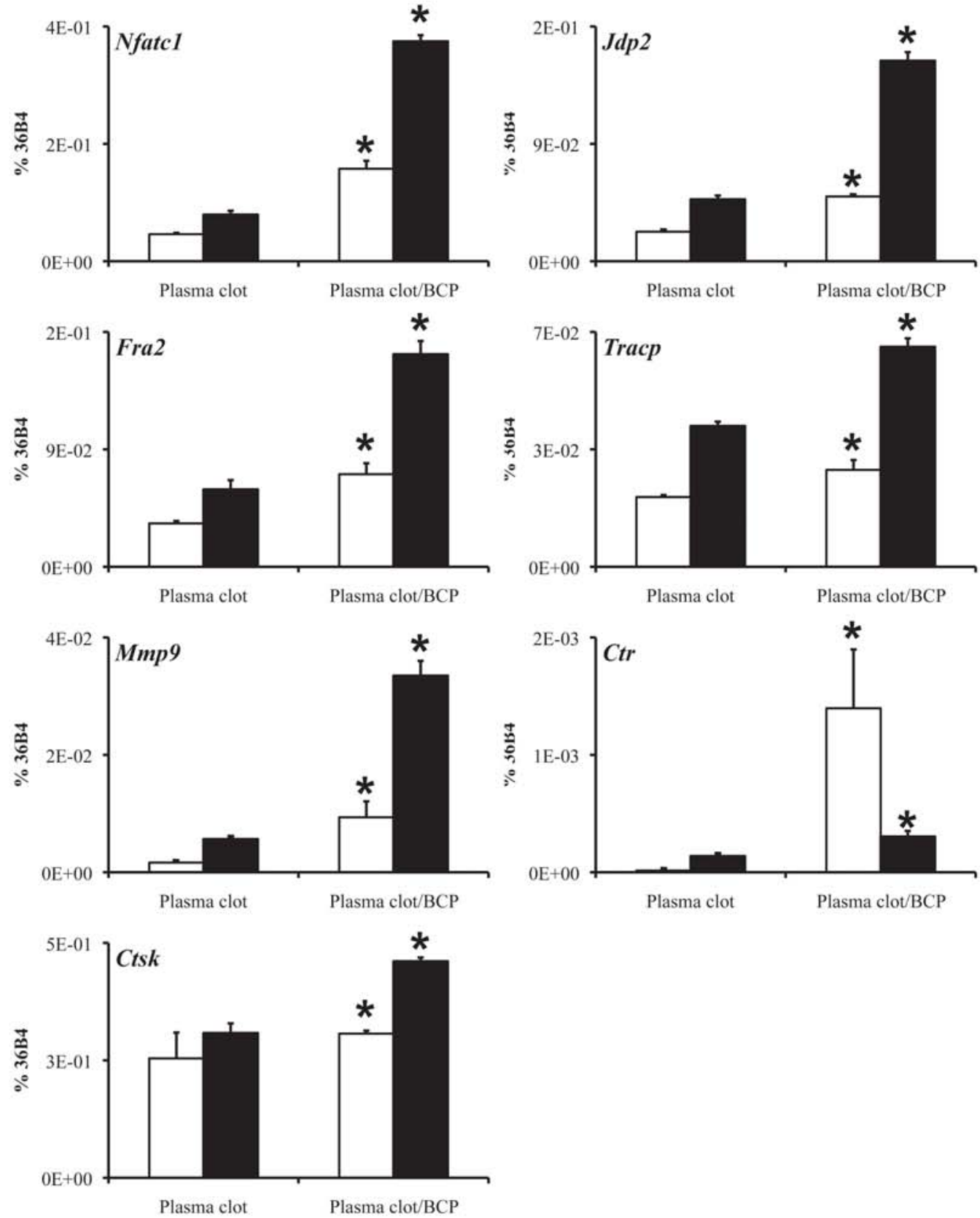
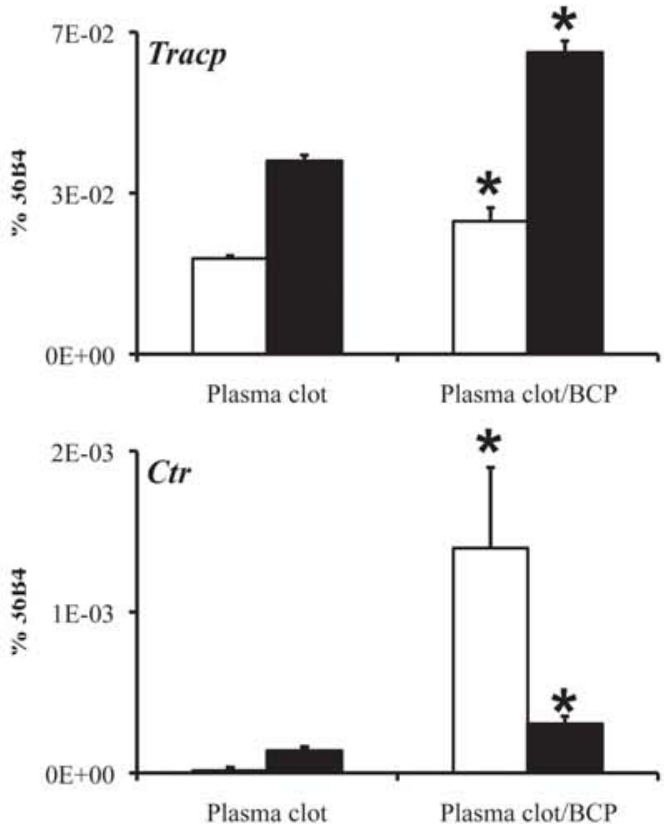

Fig. 1. Cellular proliferation and differentiation of RAW264.7 cells cultured in 3D within plasma clot or plasma clot/ BCP microparticles composite. (a) MTT assay. Right panel: RAW264.7 cells were cultured during 5 days, in plasma clot scaffold (open circles) or in plasma clot/BCP composite (black squares). Data represent the mean +/- SD of 3 independent experiments, and five MTT measures were performed for each scaffold. Left panel: calibration curve experiment using increasing amounts of cells cultured within 3D scaffolds. (b) Real-time PCR quantification of osteoclastogenesis markers: RAW264.7 cells were cultured during 2 days (Nfatc1, Jdp2, Fra2) or 4 days (Tracp, Mmp9, Ctr, Ctsk), in the presence of $20 \mathrm{nM}$ GST protein (control, open bars) or $20 \mathrm{nM}$ GSTRANKL (black bars). Data represent the mean $+/-$ SD of 3 independent experiments, each performed in triplicate. * Statistically significant differences between plasma clot and plasma clot/BCP conditions $(p<0.05)$. 
cell culture of human monocyte-enriched fraction on plastic tissue culture plates, and we determined that 30,000 cells $/ \mathrm{cm}^{2}$ constituted an appropriate concentration to achieve osteoclastic differentiation. In addition, considering the average diameter of 80-200 $\mu \mathrm{m}$ BCP microparticles, and the number of particles present within $50 \mathrm{mg}$ of BCP, the whole of the particles corresponds to a total area of $18 \mathrm{~cm}^{2} .500,000$ cells for $\mathrm{BCP} / \mathrm{scaffolds}$ will give a final cell/surface ratio of $27,800 \mathrm{cells} / \mathrm{cm}^{2}$, close to the value we established in preliminary $2 \mathrm{D}$ experiments. All the 3D cell culture experiments were performed using this cell concentration. Plasma, cells and BCP particles were introduced into $1-\mathrm{mL}$ syringes. Clotting activation was obtained by addition of $5 \mu \mathrm{L}$ of $2 \% \mathrm{CaCl}_{2} / 2 \mathrm{H}_{2} \mathrm{O}$ solution. After $15 \mathrm{~min}$ at RT, the syringe tips were cut and the scaffolds were pushed out in 24 well cell culture plates, in $1.5 \mathrm{~mL}$ of Minimum Essential Medium Alpha Medium ( $\alpha$ MEM, Lonza) containing 5\% Hyclone serum. RAW264.7 mouse cells were differentiated in the presence of GST-RANKL at $20 \mathrm{nM}$ and GST protein was used for control condition. Human precursor cells were differentiated with a cocktail containing hM-CSF (33 ng/ $\mathrm{mL})$ and hRANKL (66 ng/mL). hM-CSF was also present in control condition. Cells were cultured up to seven days, with a renewal of the medium at day 2 .

\section{MTT assay}

Cells cultured within 3D scaffolds, were rinsed with $1 \mathrm{~mL}$ of PBS and placed into $0.5 \mathrm{~mL}$ of MEM medium without phenol red (\#12-668, Lonza) containing 5\% serum and $0.5 \mathrm{mg} / \mathrm{mL}$ of thiazolyl blue tetrazolium bromide (MTT; M5655, Sigma-Aldrich, St. Louis, MO, USA). After 1 hour in cell incubator, the medium was removed, $0.5 \mathrm{~mL}$ of lysis solution (sodium dodecyl sulphate, SDS 10\%, HCl $0.01 \mathrm{~N}$ ) was added, and incubation was continued overnight before quantification of optical density at $562 \mathrm{~nm}$. Lysates from three independent conditions were prepared. Five MTT measures were performed for each condition. MTT is not stricto sensu a proliferation marker. However, since proliferating cells are metabolically more active than nonproliferating cells, MTT is usually considered as a suitable assay for cellular growth measurements. Using increasing amounts of cells cultured within 3D scaffolds, we provide a calibration curve (Fig.1a, left panel) demonstrating the relationship between cell number and MTT assay quantification.

\section{Total RNA preparation}

Total RNAs were prepared using Trizol reagent. After a wash with $1 \mathrm{~mL}$ of PBS, 3D scaffolds were crushed by several up-and-down pipettings in $0.5 \mathrm{~mL}$ of Trizol reagent before a freezing step at $-80^{\circ} \mathrm{C}$. Samples were thawed and mixed vigorously with $0.5 \mathrm{~mL}$ of chloroform during 15 sec before a 5 min incubation on ice. Samples were centrifuged at $14000 \mathrm{rpm}$ and $4^{\circ} \mathrm{C}$ during $15 \mathrm{~min}$. Nucleic acids, in the upper aqueous phase, were precipitated using one volume of isopropanol and an incubation of at least 1 hour at $-80^{\circ} \mathrm{C}$. Following washes in $70 \%$ ethanol, pellets were resuspended in $\mathrm{H}_{2} \mathrm{O}$ and nucleic acid concentration was quantified.

\section{Real-time PCR experiments}

Reverse transcription (Superscript II/Rnase $\mathrm{H}^{-} /$Reverse transcriptase; Invitrogen, Carlsbad, CA, USA) was performed with $1 \mu \mathrm{g}$ of RNA and random primers. A tenfold dilution of cDNAs was used for amplification reactions. PCR experiments were performed using an ABI PRISM 7000 system (Applied Biosystems, Carlsbad, CA, USA), and qPCR Mastermix Plus was purchased from Eurogentec (Seraing/Liège, Belgium). Reactions were performed in a $20 \mu \mathrm{L}$ final volume using $5 \mu \mathrm{L}$ of diluted cDNAs. Amplification conditions were as follows: $50^{\circ} \mathrm{C}$, $2 \mathrm{~min} ; 95^{\circ} \mathrm{C}, 10 \mathrm{~min}$; $\left(95^{\circ} \mathrm{C}, 15 \mathrm{sec} ; 60^{\circ} \mathrm{C}, 1 \mathrm{~min}\right)$ cycled 40 times. The 36B4 housekeeping gene (Acidic Ribosomal Phosphoprotein P0) was used for normalization of the results. Data represent the mean $+/-\mathrm{SD}$ of 3 independent experiments, each performed at least in triplicate.

\section{Mouse primers}

36B4 (F5'- tccaggctttgggcatca -3'; R5'ctttatcagctgcacatcactcaga -3'; GI: 145966895), Nfatc1 (F5'tgaggctggtcttccgagtt -3'; R5'- cgctgggaacactcgatagg -3'; GI: 118131200), Jdp2 (F5'- cgctgacatccgcaacatt -3'; R5'ggcctcttgcccagtttca -3'; GI: 31982607 ), Fra2 (F5'tcgccgggagctgaca -3'; R5'- gcagctcagcaatctctttctg -3'; GI: 634059), VegfA (F5'- tttactgctgtacctccacca -3'; R5'atctctcctatgtgctggcttt -3'; GI: 160358802), VegfC (F5'gggaagaagttccaccatca -3'; R5'- atgtggccttttccaatacg -3'; GI: 119672918), Sdf1 (F5'- gagccaacgtcaagcatctg -3'; R5'cgggtcaatgcacacttgt -3'; GI: 60279259), Tracp (F5'tgcctacctgtgtggacatga -3'; R5'- cacatagcccacaccgttctc -3'; GI: 156151431), Mmp9 (F5'-tgagtccggcagacaatcct-3'; R5'cgccctggatctcagcaata -3'; GI: 31560795), Ctr (F5'cttccatgctgatcttctgg -3'; R5'- cagatctccattgggcacaa -3'; GI: 112181168) and Ctsk (F5'- cagcagaggtgtgtactatg -3'; R5'gcgttgttcttattccgagc -3'; GI: 12834089).

\section{Human primers}

36B4 (F5'- tgcatcagtaccccattctatcat -3'; R5'aggcagatggatcagccaaga -3'; GI: 49087144), NFATC1 (F5'gcatcacagggaagaccgtgtc -3'; R5'- gaagttcaatgtcggagtttctgag -3'; GI: 27502392), JDP2 (F5'- cttcttcttgttccggcatc -3'; R5'cttcctggaggtgaaactgg -3'; GI: 205277415), FRA2 (F5'tagatatgcetggctcaggcag -3'; R5'- ggttggacatggaggtgatcac -3'; GI: 44680151), VEGFA (F5'- aggaggagggcagaatcatca -3'; R5'- ctcgattggatggcagtagct -3'; GI: 284172458), VEGFC (F5'- gtgtccagtgtagatgaactc -3'; R5'atctgtagacggacacacatg -3'; GI: 19924300), SDF1 (F5'aattctcaacactccaaactgtgc -3'; R5'- tgcacacttgtctgttgttgttc 3'; GI: 164697547), TRACP (F5'- gaccaccttggcaatgtctctg -3'; R5'- tggctgaggaagtcatctgagttg -3'; GI: 161377452), MMP9 (F5'- gtgctgggetgctgctttgctg -3'; R5'gtcgccctcaaaggtttggaat -3'; GI: 74272286), CTR (F5'tggtgccaaccactatccatgc -3'; R5'- cacaagtgccgccatgacag 3'; GI: 46361988) and CTSK (F5'- tgaggettctcttggtgtccatac -3'; R5'- aaagggtgtcattactgcggg -3'; GI: 23110958).

Field-emission scanning electron microscopy analysis Plasma clot/BCP scaffolds were fixed overnight at $4^{\circ} \mathrm{C}$ in a buffered glutaraldehyde solution. The samples were rinsed, dehydrated in a graded ethanol series, immersed in 
hexamethyldisilazane (Sigma-Aldrich) for $5 \mathrm{~min}$, and dried at room temperature. The samples were then mounted on aluminium stubs and sputter coated with gold-palladium (Cressington, 308R, UK). Examination was performed using a field-emission scanning electron microscope (FESEM JEOL 6700F, Tokyo, Japan).

\section{Statistics}

All numerical data are presented as mean values together with the standard deviation. The data were statistically evaluated using the non-parametric Mann-Whitney $U$ test. Differences were considered to be statistically significant if the $p$-value was less than 0.05 .

\section{Results}

3D mouse monocyte cell line metabolic activity and differentiation within plasma clot or plasma clot/BCP microparticles composite

RAW264.7 cells were cultured during five days in scaffolds made of plasma clot or plasma clot/BCP microparticles. As shown in Fig.1a (right panel), for cells cultured within plasma clot scaffold, MTT cleavage measure slightly decreased between day 1 and day 2, before an increase up to day 4 and a stabilisation between day 4 and day 5 . When cells were grown within plasma clot/BCP microparticles scaffold, metabolic activity increased up to day 3 , decreased between day 3 and day 4, and increased again between day 4 and day 5. As a whole, MTT cleavage measure increased between day 1 and day 5 for both scaffolds, while RAW264.7 cells metabolic activity was higher within plasma clot/BCP microparticles composite compared to plasma clot scaffold. A calibration curve depicting the relationship between cell number and MTT assay quantification is provided (Fig.1a, left panel).

Using real-time PCR experiments, we next quantified the expression of marker genes of the osteoclastic differentiation. As shown in Fig. 1b, culture of these cells in plasma/BCP in the absence of RANKL, induced by itself a significant increase of the expression of all the markers tested, namely Nfatc1, Jdp2, Fra2, Tracp, Mmp9, Ctr and Ctsk, compared to culture in plasma clot alone. In response to RANKL treatment, this effect was potentiated for all the markers excepted for Ctr whose expression was downregulated.

More generally, the presence of the BCP mineral matrix in the plasma clot significantly induced an up-regulation of osteoclastogenesis markers expression for both control and RANKL-treated conditions.

\section{D human primary monocytes differentiation within plasma clot or plasma clot/BCP microparticles composite}

Human monocyte-enriched fraction was prepared as described in Materials and Methods, and cells were cultured within plasma clot or plasma clot/BCP, in the absence or in the presence of hRANKL. hM-CSF was present in both conditions. As shown in Fig.2, for cells cultured within plasma clot/BCP, hRANKL treatment upregulated the expression of NFATC1 (day 1), JDP2 (day
1) and FRA2 (day 2) genes. In plasma clot, no stimulation was observed for NFATC1 and JDP2 genes. Regarding FRA2 gene expression, hRANKL effect was 20 -fold higher within plasma clot/BCP compared to plasma clot scaffold.

We next quantified at day $5 \mathrm{hRANKL}$ impact on the expression of TRACP, MMP9, CTR and CTSK genes. For both scaffolds, TRACP and CTSK genes expression was up regulated upon hRANKL treatment. For both genes, hRANKL-induced over-stimulation observed within plasma clot/BCP matrix was statistically significant. By contrast, the expression of MMP9 and CTR genes was down regulated in response to hRANKL. For both MMP9 and CTR genes, the presence of BCP particles within plasma clot hydrogel induced an over-stimulation, particularly for CTR gene basal expression that is 9-fold higher within plasma clot/BCP.

Considering the whole set of genes tested with human progenitors, and as described above for mouse RAW264.7 cells, the presence of BCP microparticles induced a statistically significant stimulation of gene expression for both control and RANKL conditions.

\section{Pro-angiogenic and chemoattractant factor genes expression}

RAW264.7 cells (Fig.3a) or human monocyte-enriched fraction (Fig.3b) were cultured for 2 days within plasma clot or plasma clot/BCP scaffolds, and real-time PCR was used to quantify RANKL treatment impact on the expression of VegfA, VegfC and Sdf1 genes. For both mouse and human cells cultured in plasma clot alone, the expression of VegfA gene was not altered upon RANKL treatment. Conversely, culture in plasma/BCP in the presence of RANKL induced a significant down regulation of this gene compared to plasma alone. By contrast, for both species, the expression of VegfC and $S d f 1$ genes was up regulated, and $\mathrm{BCP}$ particles strongly potentiated RANKL-induced stimulation.

Regarding RANKL-induced gene expression, and compared to plasma clot, the presence of $\mathrm{BCP}$ microparticles induced a 3-fold and a 7-fold overstimulation for VegfC and $S d f 1$ genes respectively for mouse cells. This BCP effect was further enhanced in human progenitors with a 6.6-fold and a 21-fold overstimulation for VegfC and $S d f 1$ genes respectively.

Field-emission scanning electron microscopy analysis of plasma clot/BCP scaffolds seeded with human monocytes

Human monocyte-enriched fraction was cultured during 7 days within plasma clot/BCP composite, in the presence of hM-CSF (Fig.4, a, c, e) or in the presence of hM-CSF/ hRANKL (Fig.4, b, d, f). Both scaffolds were analyzed using field-emission scanning electron microscopy. As depicted in Fig.4 (a-d), we observed BCP microparticles embedded within a matrix made of fibrin fibers. We observed also that the fibrin matrix was substantially denser within hM-CSF/hRANKL scaffolds (b, d) when compared to hM-CSF scaffolds $(\mathrm{a}, \mathrm{c})$. At higher magnification we observed cells on BCP microparticles (e-f, white arrows), as well as cell processes interacting with the BCP surface (f). 

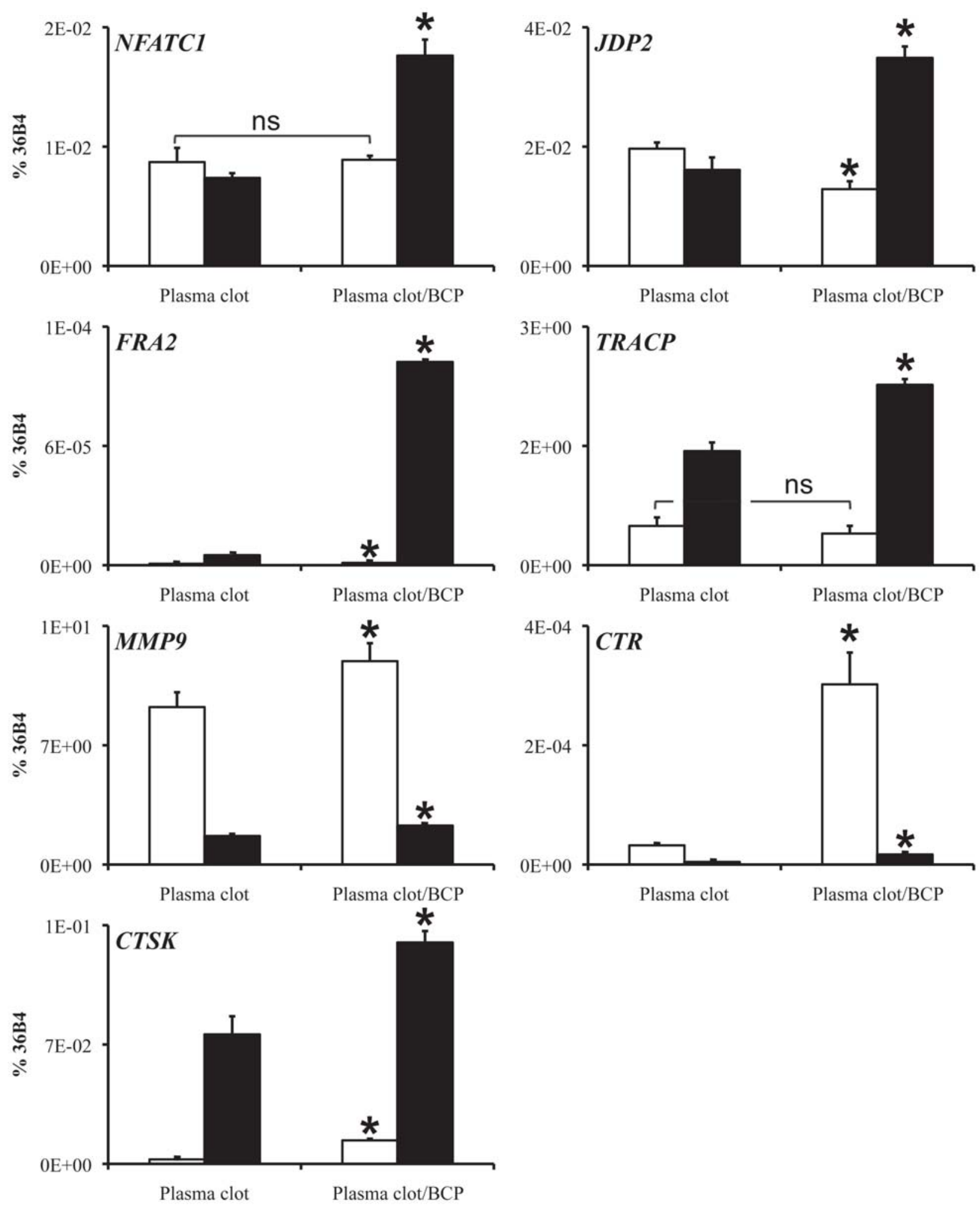

Fig. 2. Osteoclastic differentiation of human primary monocytes cultured in 3D within plasma clot or plasma clot/ BCP microparticles composite. Real-time PCR quantification of osteoclastogenesis markers: human monocyteenriched fraction was cultured during 1 day (NFATC1, JDP2), 2 days (FRA2) or 5 days (TRACP, MMP9, CTR, CTSK) with $33 \mathrm{ng} / \mathrm{mL} \mathrm{hMCSF}$, in the absence (control, open bars) or in the presence of $66 \mathrm{ng} / \mathrm{mL}$ hRANKL (black bars). Data represent the mean $+/-$ SD of 3 independent experiments, each performed in triplicate. * Statistically significant differences between plasma clot and plasma clot/BCP conditions $(p<0.05)$; ns, non-significant. 
$\mathrm{a}$
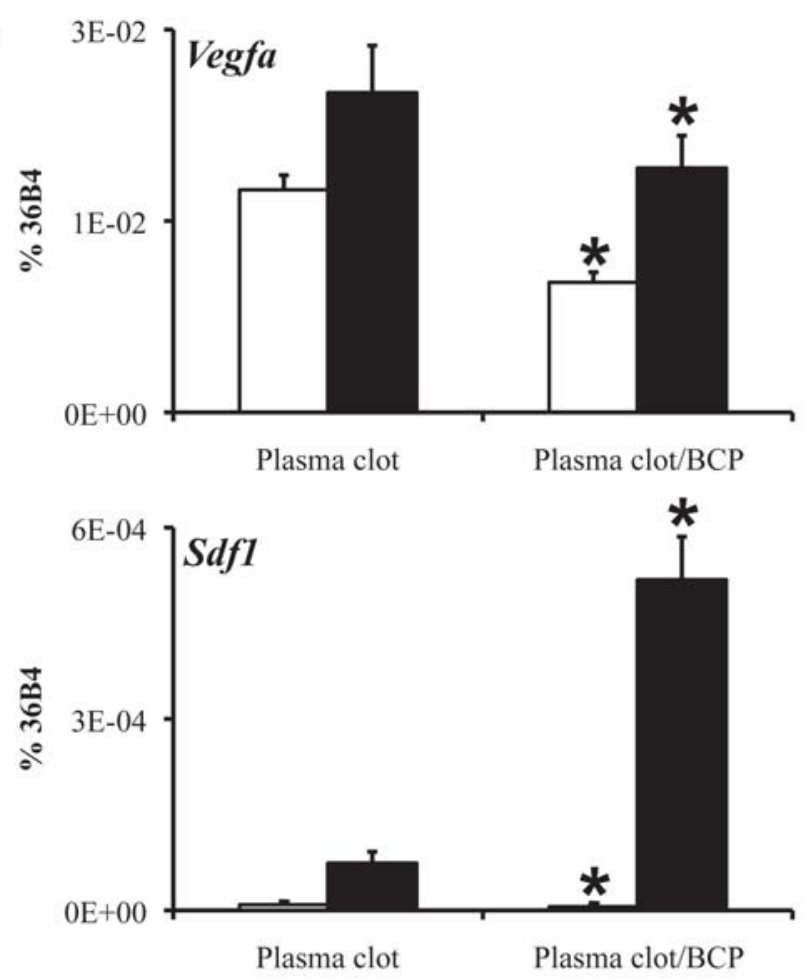

b
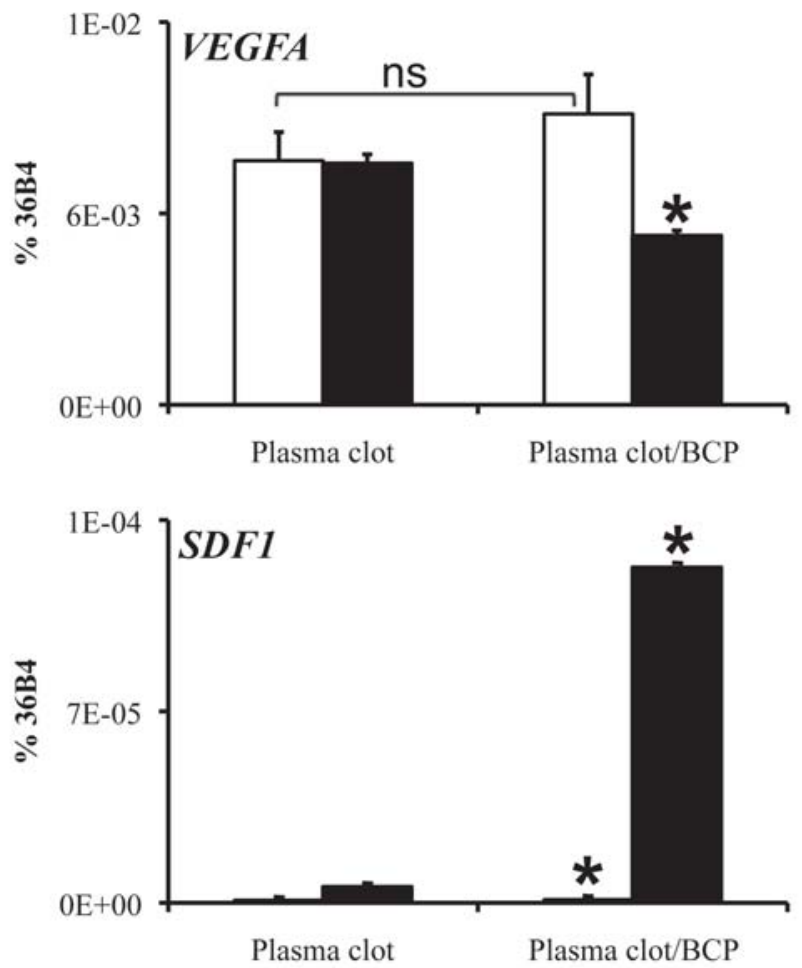
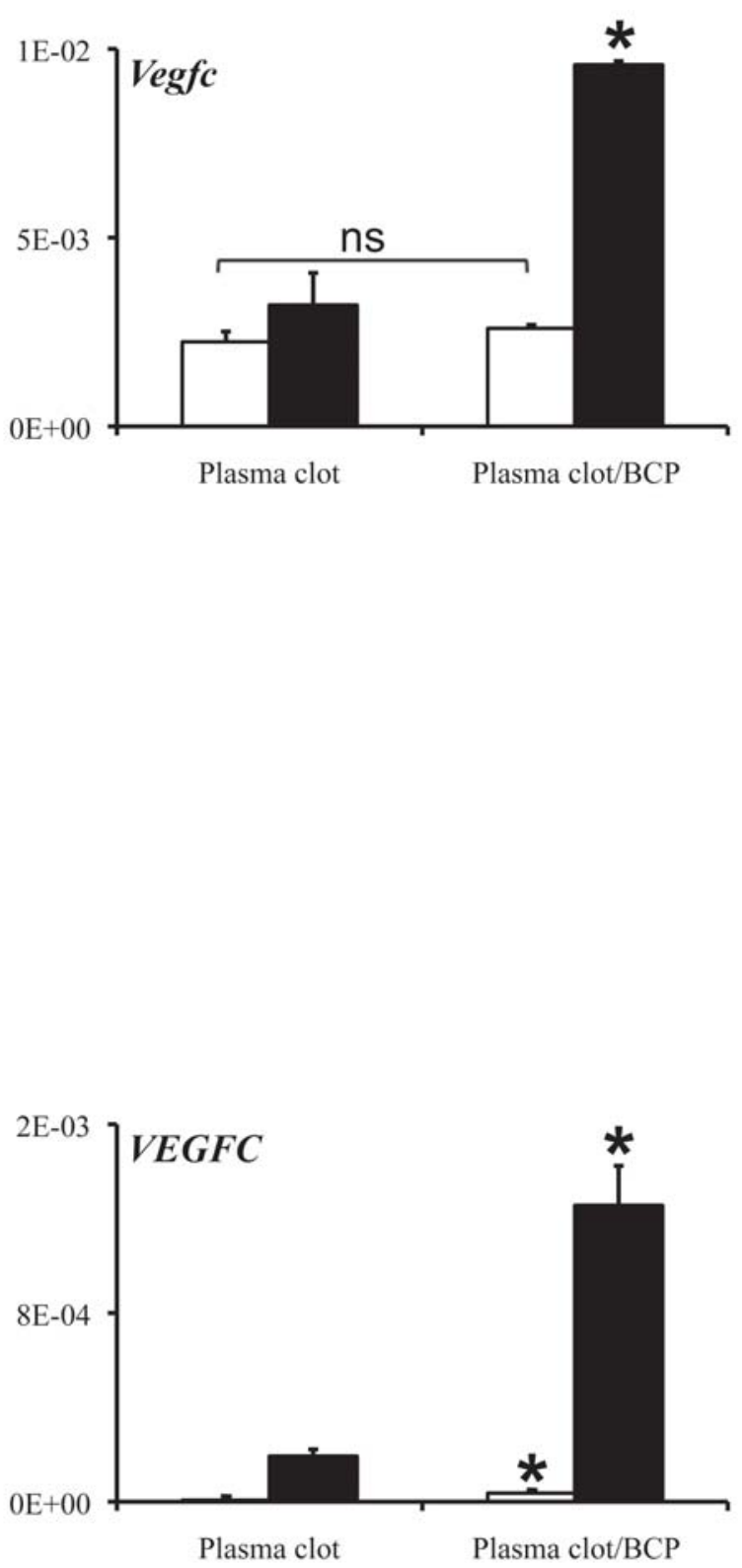

Fig. 3. Pro-angiogenic and chemoattractant factors production by monocytes cultured in $3 \mathrm{D}$ within plasma clot or plasma clot/BCP microparticles composite. Real-time PCR quantification: mouse RAW264.7 cells (a) were cultured during 2 days in the presence of $20 \mathrm{nM}$ GST protein (control, open bars) or $20 \mathrm{nM}$ GSTRANKL (black bars). Human monocyte-enriched fraction (b) were cultured during 2 days with $33 \mathrm{ng} / \mathrm{mL} \mathrm{hM}-\mathrm{CSF}$, in the absence (control, open bars) or in the presence of $66 \mathrm{ng} / \mathrm{mL}$ hRANKL (black bars). Data represent the mean $+/$ - SD of 3 independent experiments, each performed in triplicate. * Statistically significant differences between plasma clot and plasma clot/BCP conditions $(p<0.05)$; ns, non-significant. 

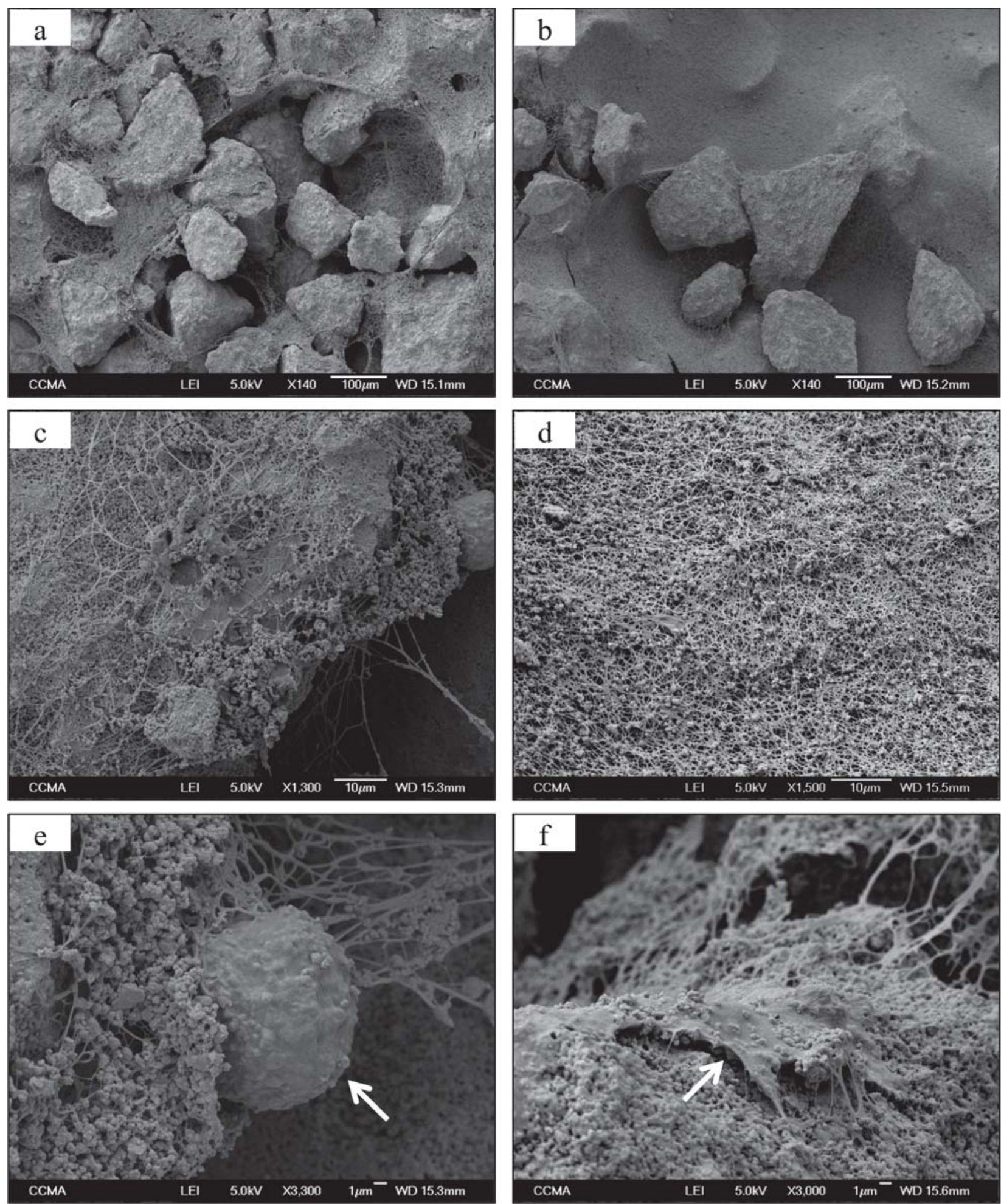

Fig. 4. Field-emission scanning electron microscopy analysis of plasma clot/BCP scaffolds seeded with human monocytes. Human monocyte-enriched fraction was cultured during 7 days within plasma clot/BCP microparticles composite, in the presence of hM-CSF (a, c, e) or in the presence of hM-CSF/hRANKL (b, d, f). White arrows: cells attached at the surface of BCP microparticles. Scale bars: $100 \mu \mathrm{m}$ (a, b), $10 \mu \mathrm{m}$ (c, d) and $1 \mu \mathrm{m}$ (e, f).

\section{Discussion}

In the present study, we wanted to investigate the impact of a plasma clot/BCP microparticles composite on mouse and human monocytes, and more precisely on their differentiation into osteoclasts. Using the plasma clot/BCP microparticles composite as a 3D cell culture system, we wanted to identify molecules, which could account for the osteogenic property of this biomaterial. Hypothesizing that osteoclast progenitors could participate to the proosteogenic effect of mononuclear cells we observed previously (Balaguer et al., 2010), we focused on this population and we used plasma as a source of fibrin to avoid a contamination by other cell types present within total blood. We demonstrate in the present report that plasma clot/BCP microparticles composite provided 
monocytes with a suitable microenvironment allowing their osteoclastic differentiation in vitro, together with the production of pro-angiogenic and chemoattractant factors, namely VegfC and Sdf1. It will be interesting to mix osteoclast progenitors with different cell populations such as lymphocytes, platelets or granulocytes. This would bring to light the impact of these different blood cell populations on osteoclast progenitors differentiation within plasma clot/ BCP microparticles, and more specifically on the production of pro-angiogenic molecules and mesenchymal stem cells chemoattractant factors.

For both mouse and human monocytes, the expression of early differentiation marker genes (Nfactc1, Jdp2, Fra2) was stimulated upon RANKL treatment within plasma clot or plasma clot/BCP scaffolds. Additionally, BCP exerted a strong stimulatory effect, both on basal and RANKLinduced Nfactc1, Jdp2 and Fra2 genes expression. Regarding Tracp gene, RANKL treatment induced its upregulation whatever the scaffold or the species and, as we observed for the early genes, RANKL effect was potentiated by the presence of BCP particles. To the best of our knowledge the effect of $\mathrm{BCP}$ on bone cell differentiation has been described for mesenchymal cell and osteoblast but never for hematopoietic precursors and osteoclasts. To explain this BCP action, we hypothesize that $\mathrm{BCP}$ microparticles likely provide osteoclast precursors with an appropriate substratum, allowing cells to interact with a surface mimicking an essential part of bone microenvironment i.e. mineralized substrate. In addition, as discussed below, these data are reminiscent of BCP effect on Sdf1 gene expression, and the study from Grassi et al. (2003).

Depending on the species (human vs. mouse), some differences were observed for the expression of other marker genes such as Mmp9 and Ctsk. Mmp9 is a matrix metalloproteinase, which facilitates the migration of osteoclasts towards bone surface through proteoglycanrich matrices (Ishibashi et al., 2006). Cathepsin $\mathrm{K}$ is abundantly and almost exclusively expressed by osteoclasts (Littlewood-Evans et al., 1997). Due to this preferential localization, and to its ability to act at an acidic and neutral $\mathrm{pH}$, cathepsin $\mathrm{K}$ is regarded as the main protease degrading most of the bone matrix (Georges et al., 2009). In mouse RAW264.7 cells, Mmp9 gene expression was induced upon RANKL treatment, whatever the cell culture support used (plasma clot or plasma clot/ BCP scaffolds). We observed also a BCP microparticlesinduced upregulation of $M m p 9$ gene expression measured in control condition or upon RANKL treatment. By contrast, for human monocytes and for both scaffolds, Mmp9 gene expression was down regulated upon RANKL treatment. This disparity could be linked to the type of cells (a cell line vs. primary monocytes) and/or to the species (human vs. mouse). Interestingly, we observed that when human monocytes were cultured in the presence of hRANKL in plasma/BCP scaffolds (Fig.4, b and d) the fibrin matrix was substantially denser than in the absence of hRANKL (Fig.4, a and c). This could be linked with the down-regulation of MMP9 gene expression we measured within human cells upon hRANKL treatment.
This hypothesis is supported by the study from Lelong et al. (2001) reporting the fibrinolytic activity of MMP9 protease.

Regarding the Ctsk gene, its expression was strongly stimulated upon RANKL treatment in human monocytes compared to mouse cells (9.4-fold and 1.5-fold increase respectively). As we observed for other differentiation marker genes, BCP microparticles significantly upregulated Ctsk gene expression. Concerning Ctr gene expression, in the absence of RANKL treatment, and whatever the species origin of the cells, BCP induced a significant increase of basal gene expression. Upon RANKL addition, we observed a marked downregulation for both mouse and human monocytes. More generally, the variations of gene expression we observed between species or cell culture support could be related to perturbations created by in vitro cell culture, as reviewed by Birgersdotter et al. (2005).

For both mouse and human monocytes, we report a strong stimulatory effect of BCP microparticles on RANKL-induced VegfC gene expression. This observation is of particular importance regarding the relationships between osteoclasts, angiogenesis and bone tissue formation. Indeed, osteoclasts express VEGF receptors (Tombran-Tink and Barnstable, 2004), and VEGF is able to stimulate their survival, differentiation and resorption activity (Yang et al., 2008). Concerning VegfC gene more specifically, the product of this RANKL target gene functions as an autocrine factor regulating osteoclast activity (Zhang et al., 2008). In addition, osteoclasts secrete angiogenic factors and are able to stimulate angiogenesis. Previous studies have shown that several bisphosphonates, in parallel to the inhibition of osteoclast activity, also decrease angiogenesis within tumours (Cackowski and Roodman, 2007). Osteoclasts are involved in osteoclast and endothelial cell invasiveness, and in the bio distribution of VEGF (vascular endothelial growth factor) bound to the extracellular matrix (Delaisse et al., 2000; Engsig et al., 2000). Concerning bone tissue engineering, several studies report that VEGF delivery, alone or in combination with other factors, is beneficial to bone formation in ectopic site ( Peng et al., 2002; Huang et al., 2005; Peng et al., 2005; ) or within bone defects (Geiger et al., 2005; Ito et al., 2005; Kaigler et al., 2006; Clarke et al., 2007). More recently, Wernike et al. (2010) reported that VEGF incorporated into calcium phosphate ceramics promoted vascularisation and bone formation in vivo.

As mentioned above, we observed in response to RANKL a strong stimulation of VegfC gene expression. By contrast, VegfA gene expression was not significantly modulated by RANKL. While VegfA is involved in angiogenesis control through VegfR1 and VegfR2, VegfC is a specific ligand for VegfR3 and regulates lymphangiogenesis (Otrock et al., 2007; Shibuya and Claesson-Welsh, 2006). However, VegfC can undergo proteolytical cleavage, and this processed form binds and activates VegfR2 (Joukov et al., 1996). VegfC is also able to induce angiogenesis in vivo (Cao et al., 1998), and the mechanism underlying this effect may involve the recruitment of VegfA-secreting macrophages (Chung et 
al., 2009). Considering that VegfC may act directly and indirectly on VegfA/VegfR1/VegfR2 signalisation, VegfC gene up-regulation within plasma clot/BCP composite could have a beneficial effect in vivo on bone repair through the recruitment of endothelial cells and the formation of new vessels.

At last, due to the presence of BCP particles, we observed for both mouse and human monocytes a dramatic stimulation of RANKL-induced $S d f 1$ gene expression within plasma clot/BCP scaffold. This is reminiscent of the Grassi et al. (2003) study, demonstrating that human $\mathrm{CD}_{11} \mathrm{~b}^{+}$osteoclast progenitors grown on plastic or on phosphate-coated slides differentially expressed a panel of chemokines/receptors. Interestingly, the authors found that SDF1 (CXCL12) significantly increased only when cells were differentiated on phosphate-coated slides. In addition, Sdf1 is induced in the periosteum of injured bone, and Sdf1/CXCR4 signalling is critical for mesenchymal stem cells recruitment to the fracture site where they participate in endochondral bone repair (Kitaori et al., 2009). As a whole, we demonstrate that osteoclast differentiation within plasma clot/BCP scaffold is associated with the expression of $S d f 1$ gene, which encodes for a chemotactic factor that allows mesenchymal stem cells homing both in vitro and in vivo (Deschaseaux et al., 2009; Karp and Leng Teo, 2009).

Although the role of osteoclast/osteoblast coupling in normal bone remodelling is established, the beneficial effect of inducing osteoclast differentiation in addition to osteoblast differentiation for bone reconstruction in bone tissue engineering has been very recently hypothesized. Considering physiological remodelling in a normal adult skull, new bone formation by the osteoblasts occurs almost exclusively at sites previously resorbed by osteoclasts (Karsdal et al., 2007), and osteoclasts secrete factors able to induce osteoblast differentiation and to increase osteoblast activity (Karsdal et al., 2008). In addition, alterations caused by micro-cracks in bone induce first bone resorption through the recruitment of osteoclasts and secondary bone formation (Segovia-Silvestre et al., 2009). More recently, Brouard et al. (2010) reported that G-CSF increased multipotent mesenchymal precursor cells number in bone marrow via an indirect mechanism involving osteoclast-mediated bone resorption. Moreover, Ortega et al (2010) described the complementary interplay between matrix metalloproteinase-9, vascular endothelial growth factor and osteoclast functions, these interactions driving endochondral bone formation. At last, a recent report from Park et al. (2010) establishes that scaffold degradation rate directly impacts the metabolism of human bone marrow derived mesenchymal stem cells, and in turn, the rate of osteogenesis.

As a whole, for both human and mouse monocytes, we demonstrate in the present report that plasma clot/BCP scaffold potentiates the expression of marker genes of osteoclastogenesis such as Nfactc1, Jdp2, Fra2, Tracp and Ctsk. In addition, for both mouse and human precursors, osteoclastic differentiation was associated with a strong stimulation of VegfC and $S d f 1$ genes expression. Thus, we demonstrate that plasma clot/BCP microparticles composite provided monocytes with a suitable microenvironment allowing their osteoclastic differentiation in vitro, together with the production of proangiogenic and chemoattractant factors. Further experiments are required to investigate, both in vitro and in vivo, the relationships between osteoclastogenesis within plasma clot/BCP composite and osteogenic properties of this biomaterial.

\section{Acknowledgments}

This work was supported by funding from the Nice University, CNRS, Graftys SA (Aix-en-Provence, France) and INSERM. A co-funding from the CNRS and from Graftys SA supported C.C.M.

\section{References}

Alam I, Asahina I, Ohmamiuda K, Enomoto S (2001) Comparative study of biphasic calcium phosphate ceramics impregnated with rhBMP-2 as bone substitutes. J Biomed Mater Res 54: 129-138.

Arrington ED, Smith WJ, Chambers HG, Bucknell AL, Davino NA (1996) Complications of iliac crest bone graft harvesting. Clin Orthop Relat Res (329): 300-309.

Aulakh TS, Jayasekera N, Kuiper JH, Richardson JB (2009) Long-term clinical outcomes following the use of synthetic hydroxyapatite and bone graft in impaction in revision hip arthroplasty. Biomaterials 30: 1732-1738.

Balaguer T, Boukhechba F, Clavé A, Bouvet-Gerbettaz S, Trojani C, Michiels JF, Laugier JP, Bouler JM, Carle GF, Scimeca JC, Rochet N (2010) Biphasic calcium phosphate micro-particles for bone formation: benefits of combination with blood clot. Tissue Eng Part A 16: 3495 3505 .

Beranger GE, Momier D, Guigonis JM, Samson M, Carle GF, Scimeca JC (2007) Differential binding of poly(ADP-Ribose) polymerase- 1 and JunD/Fra2 accounts for RANKL-induced Tcirg1 gene expression during osteoclastogenesis. J Bone Miner Res 22: 975-983.

Birgersdotter A, Sandberg R, Ernberg I (2005) Gene expression perturbation in vitro - a growing case for threedimensional (3D) culture systems. Semin Cancer Biol 15: 405-412.

Brouard N, Driessen R, Short B, Simmons PJ (2010) G-CSF increases mesenchymal precursor cell numbers in the bone marrow via an indirect mechanism involving osteoclast-mediated bone resorption. Stem Cell Res 5: 6575.

Cackowski FC, Roodman GD (2007) Perspective on the osteoclast: an angiogenic cell? AnnNY Acad Sci 1117: 12-25.

Cao Y, Linden P, Farnebo J, Cao R, Eriksson A, Kumar V, Qi JH, Claesson-Welsh L, Alitalo K (1998) Vascular endothelial growth factor $\mathrm{C}$ induces angiogenesis in vivo. Proc Natl Acad Sci U S A 95: 14389-14394.

Cavagna R, Daculsi G, Bouler JM (1999) Macroporous calcium phosphate ceramic: a prospective study of 106 cases in lumbar spinal fusion. J Long Term Eff Med Implants, 9: 403-412. 
Chung ES, Chauhan SK, Jin Y, Nakao S, HafeziMoghadam A, van Rooijen N, Zhang Q, Chen L, Dana R (2009) Contribution of macrophages to angiogenesis induced by vascular endothelial growth factor receptor-3specific ligands. Am J Pathol 175: 1984-1992.

Claase MB, de Bruijn JD, Grijpma DW, Feijen J (2007) Ectopic bone formation in cell-seeded poly(ethylene oxide)/poly(butylene terephthalate) copolymer scaffolds of varying porosity. J Mater Sci Mater Med 18: 1299-1307.

Clarke SA, Hoskins NL, Jordan GR, Marsh DR (2007) Healing of an ulnar defect using a proprietary TCP bone graft substitute, JAX, in association with autologous osteogenic cells and growth factors. Bone 40: 939-947.

Cordaro L, Bosshardt DD, Palattella P, Rao W, Serino G, Chiapasco M (2008) Maxillary sinus grafting with BioOss or Straumann Bone Ceramic: histomorphometric results from a randomized controlled multicenter clinical trial. Clin Oral Implants Res 19: 796-803.

Cordonnier T, Layrolle P, Gaillard J, Langonne A, Sensebe L, Rosset P, Sohier J (2010) 3D environment on human mesenchymal stem cells differentiation for bone tissue engineering. J Mater Sci Mater Med 21: 981-987.

De Long WG, Jr., Einhorn TA, Koval K, McKee M, Smith W, Sanders R, Watson T (2007) Bone grafts and bone graft substitutes in orthopaedic trauma surgery. A critical analysis. J Bone Joint Surg Am 89: 649-658.

Delaisse JM, Engsig MT, Everts V, del Carmen Ovejero M, Ferreras M, Lund L, Vu TH, Werb Z, Winding B, Lochter A, Karsdal MA, Troen T, Kirkegaard T, Lenhard T, Heegaard AM, Neff L, Baron R, Foged NT (2000) Proteinases in bone resorption: obvious and less obvious roles. Clin Chim Acta 291: 223-234.

Deschaseaux F, Sensebe L, Heymann D (2009) Mechanisms of bone repair and regeneration. Trends Mol Med 15: 417-429.

Dupraz A, Delecrin J, Moreau A, Pilet P, Passuti N (1998) Long-term bone response to particulate injectable ceramic. J Biomed Mater Res 42: 368-375.

Engsig MT, Chen QJ, Vu TH, Pedersen AC, Therkidsen B, Lund LR, Henriksen K, Lenhard T, Foged NT, Werb Z, Delaisse JM (2000) Matrix metalloproteinase 9 and vascular endothelial growth factor are essential for osteoclast recruitment into developing long bones. J Cell Biol 151: 879-889.

Fellah BH, Josselin N, Chappard D, Weiss P, Layrolle $P$ (2007) Inflammatory reaction in rats muscle after implantation of biphasic calcium phosphate micro particles. J Mater Sci Mater Med 18: 287-294.

Fellah BH, Weiss P, Gauthier O, Rouillon T, Pilet P, Daculsi G, Layrolle P (2006) Bone repair using a new injectable self-crosslinkable bone substitute. J Orthop Res 24: 628-635.

Frenken JW, Bouwman WF, Bravenboer N, Zijderveld SA, Schulten EA, ten Bruggenkate CM (2010) The use of Straumann Bone Ceramic in a maxillary sinus floor elevation procedure: a clinical, radiological, histological and histomorphometric evaluation with a 6-month healing period. Clin Oral Implants Res 21: 201-208.

Friedmann A, Dard M, Kleber BM, Bernimoulin JP, Bosshardt DD (2009) Ridge augmentation and maxillary sinus grafting with a biphasic calcium phosphate: histologic and histomorphometric observations. Clin Oral Implants Res 20: 708-714.

Froum SJ, Wallace SS, Cho SC, Elian N, Tarnow DP (2008) Histomorphometric comparison of a biphasic bone ceramic to anorganic bovine bone for sinus augmentation: 6- to 8-month postsurgical assessment of vital bone formation. A pilot study. Int J Periodontics Restorative Dent 28: 273-281.

Gauthier O, Boix D, Grimandi G, Aguado E, Bouler JM, Weiss P, Daculsi G (1999a) A new injectable calcium phosphate biomaterial for immediate bone filling of extraction sockets: a preliminary study in dogs. J Periodontol 70: 375-383.

Gauthier O, Bouler JM, Weiss P, Bosco J, Daculsi G, Aguado E (1999b) Kinetic study of bone ingrowth and ceramic resorption associated with the implantation of different injectable calcium-phosphate bone substitutes. J Biomed Mater Res 47: 28-35.

Gauthier O, Muller R, von Stechow D, Lamy B, Weiss P, Bouler JM, Aguado E, Daculsi G (2005) In vivo bone regeneration with injectable calcium phosphate biomaterial: a three-dimensional micro-computed tomographic, biomechanical and SEM study. Biomaterials 26: 5444-5453.

Geiger F, Bertram H, Berger I, Lorenz H, Wall O, Eckhardt C, Simank HG, Richter W (2005) Vascular endothelial growth factor gene-activated matrix (VEGF165-GAM) enhances osteogenesis and angiogenesis in large segmental bone defects. J Bone Miner Res 20: 2028-2035.

Georges S, Ruiz Velasco C, Trichet V, Fortun Y, Heymann D, Padrines M (2009) Proteases and bone remodelling. Cytokine Growth Factor Rev 20: 29-41.

Grassi F, Piacentini A, Cristino S, Toneguzzi S, Cavallo C, Facchini A, Lisignoli G (2003) Human osteoclasts express different $\mathrm{CXC}$ chemokines depending on cell culture substrate: molecular and immunocytochemical evidence of high levels of CXCL10 and CXCL12. Histochem Cell Biol 120: 391-400.

Henriksen K, Neutzsky-Wulff AV, Bonewald LF, Karsdal MA (2009) Local communication on and within bone controls bone remodeling. Bone 44: 1026-1033.

Huang YC, Kaigler D, Rice KG, Krebsbach PH, Mooney DJ (2005) Combined angiogenic and osteogenic factor delivery enhances bone marrow stromal cell-driven bone regeneration. J Bone Miner Res 20: 848-857.

Ishibashi O, Niwa S, Kadoyama K, Inui T (2006) MMP-9 antisense oligodeoxynucleotide exerts an inhibitory effect on osteoclastic bone resorption by suppressing cell migration. Life Sci 79: 1657-1660.

Ito H, Koefoed M, Tiyapatanaputi P, Gromov K, Goater JJ, Carmouche J, Zhang X, Rubery PT, Rabinowitz J, Samulski RJ, Nakamura T, Soballe K, O'Keefe RJ, Boyce BF, Schwarz EM (2005) Remodeling of cortical bone allografts mediated by adherent rAAV-RANKL and VEGF gene therapy. Nature Medicine 11: 291-297.

Joukov V, Pajusola K, Kaipainen A, Chilov D, Lahtinen I, Kukk E, Saksela O, Kalkkinen N, Alitalo K (1996) A novel vascular endothelial growth factor, VEGF-C, is a ligand for the Flt4 (VEGFR-3) and KDR (VEGFR-2) receptor tyrosine kinases. EMBO J 15: 290-298. 
Kaigler D, Wang Z, Horger K, Mooney DJ, Krebsbach PH (2006) VEGF scaffolds enhance angiogenesis and bone regeneration in irradiated osseous defects. J Bone Miner Res 21: 735-744.

Karp JM, Leng Teo GS (2009) Mesenchymal stem cell homing: the devil is in the details. Cell Stem Cell 4: 206216.

Karsdal MA, Martin TJ, Bollerslev J, Christiansen C, Henriksen K (2007) Are nonresorbing osteoclasts sources of bone anabolic activity? J Bone Miner Res 22: 487-494.

Karsdal MA, Neutzsky-Wulff AV, Dziegiel MH, Christiansen C, Henriksen K (2008) Osteoclasts secrete non-bone derived signals that induce bone formation. Biochem Biophys Res Commun 366: 483-488.

Kitaori T, Ito H, Schwarz EM, Tsutsumi R, Yoshitomi H, Oishi S, Nakano M, Fujii N, Nagasawa T, Nakamura T (2009) Stromal cell-derived factor $1 /$ CXCR4 signaling is critical for the recruitment of mesenchymal stem cells to the fracture site during skeletal repair in a mouse model. Arthritis Rheum 60: 813-823.

Lelongt B, Bengatta S, Delauche M, Lund LR, Werb Z, Ronco PM (2001) Matrix metalloproteinase 9 protects mice from anti-glomerular basement membrane nephritis through its fibrinolytic activity. Journal Exp Med 193: 793 802.

Lerouxel E, Weiss P, Giumelli B, Moreau A, Pilet P, Guicheux J, Corre P, Bouler JM, Daculsi G, Malard O (2006) Injectable calcium phosphate scaffold and bone marrow graft for bone reconstruction in irradiated areas: an experimental study in rats. Biomaterials 27: 4566-4572.

Lindgren C, Hallman M, Sennerby L, Sammons R (2010) Back-scattered electron imaging and elemental analysis of retrieved bone tissue following sinus augmentation with deproteinized bovine bone or biphasic calcium phosphate. Clin Oral Implants Res, in press.

Lindgren C, Sennerby L, Mordenfeld A, Hallman M (2009) Clinical histology of microimplants placed in two different biomaterials. Int J Oral Maxillofac Implants 24: 1093-1100.

Linton JL, Sohn BW, Yook JI, Le Geros RZ (2002) Effects of calcium phosphate ceramic bone graft materials on permanent teeth eruption in beagles. Cleft Palate Craniofac J 39: 197-207.

Littlewood-Evans A, Kokubo T, Ishibashi O, Inaoka T, Wlodarski B, Gallagher JA, Bilbe G (1997) Localization of cathepsin $\mathrm{K}$ in human osteoclasts by in situ hybridization and immunohistochemistry. Bone 20: 81-86.

Lu J, Blary MC, Vavasseur S, Descamps M, Anselme K, Hardouin P (2004) Relationship between bioceramics sintering and micro-particles-induced cellular damages. J Mater Sci Mater Med 15: 361-365.

Malard O, Bouler JM, Guicheux J, Heymann D, Pilet P, Coquard C, Daculsi G (1999) Influence of biphasic calcium phosphate granulometry on bone ingrowth, ceramic resorption, and inflammatory reactions: preliminary in vitro and in vivo study. J Biomed Mater Res, 46:103-111.

Ortega N, Wang K, Ferrara N, Werb Z, Vu TH (2010) Complementary interplay between matrix metalloproteinase-9, vascular endothelial growth factor and osteoclast function drives endochondral bone formation. Dis Model Mech 3: 224-235.

Otrock ZK, Makarem JA, Shamseddine AI (2007) Vascular endothelial growth factor family of ligands and receptors: review. Blood Cells Mol Dis 38: 258-268.

Park SH, Gil ES, Kim HJ, Lee K, Kaplan DL (2010) Relationships between degradability of silk scaffolds and osteogenesis. Biomaterials 31: 6162-6172.

Peng H, Usas A, Olshanski A, Ho AM, Gearhart B, Cooper GM, Huard J (2005) VEGF improves, whereas sFlt1 inhibits, BMP2-induced bone formation and bone healing through modulation of angiogenesis. J Bone Miner Res 20:2017-2027.

Peng H, Wright V, Usas A, Gearhart B, Shen HC, Cummins J, Huard J (2002) Synergistic enhancement of bone formation and healing by stem cell-expressed VEGF and bone morphogenetic protein-4. J Clin Invest 110: 751 759 .

Piattelli A, Scarano A, Mangano C (1996) Clinical and histologic aspects of biphasic calcium phosphate ceramic (BCP) used in connection with implant placement. Biomaterials 17: 1767-1770.

Ransford AO, Morley T, Edgar MA, Webb P, Passuti N, Chopin D, Morin C, Michel F, Garin C, Pries D (1998) Synthetic porous ceramic compared with autograft in scoliosis surgery. A prospective, randomized study of 341 patients. J Bone Joint Surg Br 80: 13-18.

Saldana L, Sanchez-Salcedo S, Izquierdo-Barba I, Bensiamar F, Munuera L, Vallet-Regi M, Vilaboa N (2009) Calcium phosphate-based particles influence osteogenic maturation of human mesenchymal stem cells. Acta Biomater 5: 1294-1305.

Sculean A, Windisch P, Szendroi-Kiss D, Horvath A, Rosta P, Becker J, Gera I, Schwarz F (2008) Clinical and histologic evaluation of an enamel matrix derivative combined with a biphasic calcium phosphate for the treatment of human intrabony periodontal defects. J Periodontol 79: 1991-1999.

Seeman E, Delmas PD (2006) Bone quality - the material and structural basis of bone strength and fragility. N Engl J Med 354: 2250-2261.

Segovia-Silvestre T, Neutzsky-WulffAV, Sorensen MG, Christiansen C, Bollerslev J, Karsdal MA, Henriksen K (2009) Advances in osteoclast biology resulting from the study of osteopetrotic mutations. Hum Genet 124: 561577.

Sen MK, Miclau T (2007) Autologous iliac crest bone graft: should it still be the gold standard for treating nonunions? Injury 38 Suppl 1: S75-80.

Shibuya M, Claesson-Welsh L (2006) Signal transduction by VEGF receptors in regulation of angiogenesis and lymphangiogenesis. Exp Cell Res 312: 549-560.

Silva SN, Pereira MM, Goes AM, Leite MF (2003) Effect of biphasic calcium phosphate on human macrophage functions in vitro. J Biomed Mater Res A 65: 475-481.

Tombran-Tink J, Barnstable CJ (2004) Osteoblasts and osteoclasts express PEDF, VEGF-A isoforms, and VEGF receptors: possible mediators of angiogenesis and matrix 
remodeling in the bone. Biochem Biophys Res Commun 316: 573-579.

Weiss P, Layrolle P, Clergeau LP, Enckel B, Pilet P, Amouriq Y, Daculsi G, Giumelli B (2007) The safety and efficacy of an injectable bone substitute in dental sockets demonstrated in a human clinical trial. Biomaterials 28: 3295-3305.

Wernike E, Montjovent MO, Liu Y, Wismeijer D, Hunziker EB, Siebenrock KA, Hofstetter W, Klenke FM (2010) VEGF incorporated into calcium phosphate ceramics promotes vascularisation and bone formation in vivo. Eur Cell Mater 19: 30-40.

Yamada S, Heymann D, Bouler JM, Daculsi G (1997) Osteoclastic resorption of biphasic calcium phosphate ceramic in vitro. J Biomed Mater Res 37: 346-352.

Yang Q, McHugh KP, Patntirapong S, Gu X, Wunderlich L, Hauschka PV (2008) VEGF enhancement of osteoclast survival and bone resorption involves VEGF receptor-2 signaling and beta3-integrin. Matrix Biol 27: 589-599.

Younger EM, Chapman MW (1989) Morbidity at bone graft donor sites. J Orthop Trauma, 3:192-195.

Zhang Q, Guo R, Lu Y, Zhao L, Zhou Q, Schwarz EM, Huang J, Chen D, Jin ZG, Boyce BF, Xing L (2008) VEGF$\mathrm{C}$, a lymphatic growth factor, is a RANKL target gene in osteoclasts that enhances osteoclastic bone resorption through an autocrine mechanism. The J Biol Chem 283: 13491-13499.

\section{Discussion with Reviewers}

Reviewer I: Since it is known that the main function of osteoclasts is to resorb apatitic bone mineral, it can be expected a priori that inclusion of biphasic calcium phosphate microparticles into plasma clot will result into upregulation of marker genes for osteoclast differentiation as plasma clot by itself does not contain any calcium phosphate that can be resorbed by osteoclasts. Could you comment on the added value of the main findings of your study?

Authors: Ceramics based on BCP are commonly used as resorbable bone substitutes but few studies investigating the interactions between osteoclasts and particulate forms are available. In the present report, using monocyte-derived osteoclast progenitors differentiated in the presence of BCP granules, we aimed at the elucidation of transcriptional profiles of genes related to osteoclastogenesis and to bone remodelling. Although $\mathrm{BCP}$-induced upregulation of the expression of osteoclast marker genes was expected, we have now demonstrated this effect, at least in vitro.

In addition, we would like to stress the findings concerning the strong stimulation of VegfC and Sdf1 genes expression observed within plasma clot/BCP microparticles composite. We established in a previous study that the osteogenic property of blood clot associated to BCP particles mostly resulted from the presence of mononuclear cells, including osteoclast progenitors present within peripheral blood monocytic cells (Balaguer et al., 2010, text reference). We identify here putative molecular mediators (VegfC and Sdf1), which could account, in part at least, for the pro-osteogenic action of mononuclear cells within blood clotted around BCP microparticles composite. Indeed, angiogenesis stimulation (VegfC), as well as the recruitment of mesenchymal stem cells (Sdf1), would favour osteogenesis within the composite, supporting eventually the biomaterial substitution by new living bone.

Reviewer II: Concerning Fig 1, MTT is not a proliferation marker but an indicator for cell metabolism. In this study the MTT test has little value because there is no calibration curve. Why did the authors not present total DNA/RNA as an indicator for cell quantity?

Authors: We agree with the reviewer, and MTT is not stricto sensu a proliferation marker. However, since proliferating cells are metabolically more active than nonproliferating cells, MTT is usually considered as a suitable assay for cellular growth measurements. It should be noted that the presence of ceramics leads to underestimated DNA quantifications, and this phenomenon is more marked when small DNA amounts representative of low cell numbers are involved. This issue has been very recently addressed by Piccinini et al., who proposed an alternative method to reliably extract and quantify DNA in ceramic-containing samples (Piccinini et al., 2010). However, since we wanted also to determine cells viability through their metabolic activity, we favoured MMT assay rather than the determination of nucleic acids content.

Reviewer II: Although this is a fundamental paper on differentiation of specific cell lines, could you please discuss the effect of BCP particles in a heterogeneous blood clot?

Authors: We recently published a report demonstrating that blot clotted around BCP microparticles had osteogenic properties, and was able to repair a $6 \mathrm{~mm}$ critical femoral defect in rat (Balaguer et al., 2010, text reference). Moreover, we established in that study that the osteogenic property of blood clot associated to BCP particles mostly resulted from the presence of mononuclear cells, including osteoclast progenitors present within peripheral blood monocytic cells. Using the plasma clot/BCP microparticles composite as a $3 \mathrm{D}$ cell culture system, we wanted in the present study to identify molecules, which could account for the osteogenic property of this biomaterial. Hypothesizing that osteoclast progenitors could participate to the pro-osteogenic effect of mononuclear cells we observed previously, we focused on this population and we used plasma as a source of fibrin, to avoid a contamination by other cell types present within total blood. We demonstrate here that plasma clot/BCP microparticles composite provided monocytes with a suitable microenvironment allowing their osteoclastic differentiation in vitro, together with the production of proangiogenic and chemoattractant factors, namely VegfC and Sdf1.

It will be interesting to mix osteoclast progenitors with different cell populations such as lymphocytes, platelets or granulocytes. This would bring to light the impact of these different blood cell populations on osteoclast progenitor differentiation within plasma clot/BCP microparticles, and more specifically on the production of 
pro-angiogenic molecules and mesenchymal stem cells chemoattractant factors. At last, further experiments are required to investigate, both in vitro and in vivo, the relationships between osteoclastogenesis within plasma clot/BCP composite and osteogenic properties of this biomaterial.

Reviewer III: Do the authors believe that adding monocytes/osteoclasts will enhance the performance of $\mathrm{CaP}$ grafts in vivo?

Authors: We believe that the presence of osteoclasts within a bone substitute will contribute to mimic the resorption phase, which occurs during physiological bone remodelling. Indeed, we observe that a colonization step by osteoclasts interacting with the BCP microparticles always precedes new bone formation within the clotted blood/BCP composite grafted in vivo. In addition, we established recently that the osteogenic property of blood clot associated to BCP particles mostly resulted from the presence of mononuclear cells, which included osteoclast progenitors present within peripheral blood monocytic cells (Balaguer et al., 2010). Data published by Spence et al. (2009) further support this putative beneficial effect due to osteoclasts, since they report that collagen synthesis by osteoblasts is increased on previously resorbed surfaces made of carbonate-substituted hydroxyapatite. It should also be noted that the same group reported previously that bone formation in a carbonate-substituted hydroxyapatite implant was inhibited by zoledronate, a bisphosphonic acid, which is an inhibitor of osteoclastic bone resorption (Spence et al., 2008).

On the other hand, in other experiments performed in the laboratory, we observed that less than $50 \%$ of grafted cells are still alive only 3 days after in vivo implantation, and this percentage dropped to less than $15 \%$ at the end of the first week (F. Boukhechba and N. Rochet, personal communication). Moreover, the addition of bone cells to a biomaterial would represent a heavy and expensive method. Thus, instead of adding monocytes/osteoclasts, we would like to favour the recruitment and the differentiation of host hematopoietic progenitor cells, which could undergo a first wave of differentiation into osteoclasts. This could be achieved by using the proosteoclastogenic molecule RANKL to functionalize the $\mathrm{CaP}$ mineral phase. Alternatively, it could be sufficient to use clotted blood/BCP composite, which already contains mononuclear cells as a source of growth factors and chemoattractant molecules, and which provide host hematopoietic progenitor cells with a microenvironment suitable for their recruitment and their osteoclastic differentiation. Further experiments are required to determine whether bone reconstruction would benefit from clotted blood/BCP composite functionalisation with proosteoclastogenic molecules.

Reviewer III: What would be the effect of non resorbable CaPs like pure HA on osteoclast-like cells and the assumed pro-osteogenic condition?
Authors: Regardless of osteoclast ability to resorb pure HA, two reports in the literature characterize osteoclastic differentiation of osteoclast progenitor cells (RAW264.7 mouse cell line) seeded on this mineral matrix (Detsch et al., 2010a,b). Two other studies using neonatal rabbit bone cells (Yamada et al., 1997) or human and rat osteoclasts (Monchau et al., 2002) describe short term culture of mature osteoclasts on pure HA. As a whole, these results suggest that pure HA could support osteoclastic differentiation or, at least, mature osteoclasts survival.

Experiments should be performed to determine whether pro-angiogenic factors and chemoattractant molecules for mesenchymal stem cells are produced when osteoclastogenesis occurs in the presence of a mineral matrix made of pure HA. Additional testing could be performed, using mineral matrices with various HA content, to investigate a potential relationship between HA percentage and the level of pro-angiogenic and chemoattractant factors production. These data obtained in vitro should help to understand what happens in vivo in terms of pro-osteogenic properties of these CaP-based mineral matrices.

\section{Additional References}

Detsch R, Hagmeyer D, Neumann M, Schaefer S, Vortkamp A, Wuelling M, Ziegler G, Epple M (2010a) The resorption of nanocrystalline calcium phosphate by osteoclast-like cells. Acta Biomater 6: 3223-3233.

Detsch R, Schaefer S, Deisinger U, Ziegler G, Seitz H, Leukers B (2010b) In vitro osteoclastic activity studies on surfaces of 3D printed calcium phosphate scaffolds. J Biomater Appl, in press.

Monchau F, Lefèvre A, Descamps M, Belquin-myrdycz A, Laffargue P, Hildebrand HF (2002) In vitro studies of human and rat osteoclast activity on hydroxyapatite, betatricalcium phosphate, calcium carbonate. Biomol Eng 19: 143-152.

Piccinini E, Sadr N, Martin I (2010) Ceramic materials lead to underestimated DNA quantifications: a method for reliable measurements. Eur Cell Mater 20: 38-44.

Spence G, Phillips S, Campion C, Brooks R, Rushton $\mathrm{N}$ (2008) Bone formation in a carbonate-substituted hydroxyapatite implant is inhibited by zoledronate: the importance of bioresorption to osteoconduction. J Bone Joint Surg Br 90: 1635-1640.

Spence G, Patel N, Brooks R, Rushton N (2009) Carbonate substituted hydroxyapatite: resorption by osteoclasts modifies the osteoblastic response. J Biomed Mater Res A 90: 217-224.

Yamada S, Heymann D, Bouler JM, Daculsi G (1997) Osteoclastic resorption of calcium phosphate ceramics with different hydroxyapatite/beta-tricalcium phosphate ratios. Biomaterials 18: 1037-1041. 